\title{
Formation and Osteoconductivity of Hydroxyapatite/Collagen Composite Films Using a Thermal Substrate Method in Aqueous Solutions
}

\author{
Kensuke Kuroda $^{1}$, Mikiko Moriyama ${ }^{1, *}$, Ryoichi Ichino ${ }^{2}$, Masazumi Okido ${ }^{1}$ and Azusa Seki ${ }^{3}$ \\ ${ }^{1}$ Department of Materials Science \& Engineering, Graduate School of Engineering, Nagoya University, Nagoya 464-8603, Japan \\ ${ }^{2}$ EcoTopia Science Institute, Nagoya University, Nagoya 464-8603, Japan \\ ${ }^{3}$ Hamri Co., Ltd., Tokyo 110-0005, Japan
}

\begin{abstract}
We have studied the formation and carried out an in vivo evaluation of hydroxyapatite (HAp)/collagen and HAp/denatured collagen (gelatin) composite coatings on titanium substrates using a thermal substrate method. The coatings were formed on commercial pure titanium rods (diameter $=2 \mathrm{~mm}$, length $=5 \mathrm{~mm}$ ) and plates (thickness $=0.3 \mathrm{~mm}$ ) using a thermal substrate method in aqueous solutions that contained $0.3 \mathrm{mM} \mathrm{Ca}\left(\mathrm{H}_{2} \mathrm{PO}_{4}\right)_{2}, 0.7 \mathrm{mM} \mathrm{CaCl}_{2}$, and a concentration of acid-soluble collagen (Type I) of $\sim 432 \mathrm{mg} \mathrm{dm}^{-3}$. The coating experiments were conducted at $40-140^{\circ} \mathrm{C}$ and $\mathrm{pH}=8$ for periods of 15 or $30 \mathrm{~min}$. The coating temperature and collagen content in the solution influenced the surface morphology and collagen (or gelatin) content in the films. A coated rod was implanted in a 10-week-old male rat's tibia with a noncoated titanium rod being used as a control. The constructs were retrieved after a period of $14 \mathrm{~d}$ postimplantation and examined for new bone formation and for tissue response in the cancellous and cortical bone parts, respectively. HAp/gelatin composite films coated at $>60^{\circ} \mathrm{C}$ showed a slight improvement in osteoconductivity in the cortical bone. In contrast, there was no improvement in the cancellous bone, compared with HAp, which had no gelatin. However, the HAp/collagen composites showed a high osteoconductivity in the cortical bone region, and this increased with increasing collagen content in the films. There was the same tendency in the cancellous bone part. However, too higher a collagen content (40 mass\%) in the films gave rise to an obvious negative osteoconductive effect. [doi:10.2320/matertrans.MRA2008459]
\end{abstract}

(Received December 11, 2008; Accepted February 26, 2009; Published April 15, 2009)

Keywords: hydroxyapatite, collagen, gelatin, hydro-coating, surface morphology, thermal substrate method, in vivo

\section{Introduction}

Calcium phosphates, and specifically hydroxyapatite $\left(\mathrm{Ca}_{10}\left(\mathrm{PO}_{4}\right)_{6}(\mathrm{OH})_{2}, \mathrm{HAp}\right)$, are of interest in bone-interfacing implant applications because of their demonstrated osteoconductive properties. ${ }^{1)}$ HAp is considered to be a bioactive material and is used in the fabrication of medical and dental implants, usually in the form of a coating on a metallic substrate to compensate for its poor intrinsic mechanical properties. However, natural bone contains HAp, and also a considerable amount of other organic components, such as collagen (about 25 mass $\%{ }^{2)}$ ). Some researchers have reported on the preparation of nanocomposites of HAp/collagen and $\mathrm{HAp} /$ gelatin, ${ }^{3-5)}$ as natural bone is considered a nanocomposite of minerals and proteins. Moreover, immobilization of collagen on implants gives a tighter fixation with the surrounding tissue, because the collagen behaves as an adhesive protein to cells because of the amino groups in the collagen molecules. ${ }^{6,7)}$ From the viewpoint of osteoconductivity, we thought that the preparation of HAp/collagen composite coatings would be a more promising approach than using coatings of HAp alone. That is to say, we expected that HAp/collagen composites would influence biological reactivity and osteoconductivity.

In general, because mammalian collagen denatures to gelatin at temperatures $>40-50^{\circ} \mathrm{C}, \mathrm{HAp} /$ collagen composites cannot be obtained using a high-temperature process. Many methods that could be used to form HAp/collagen and HAp/gelatin composites have not been reported, and these composites were usually formed as a sheet or a gel using a hydro-process (i.e., synthesis in aqueous solution). However, to the best of our knowledge, a process that can be used to

*Graduate Student, Nagoya University synthesize these composites as coated films on metallic substrates has not been reported so far. We have proposed using a hydro-coating method, the thermal substrate method, for the preparation of calcium phosphates, such as HAp, ${ }^{8)}$ and have already reported on HAp and carbonate apatite coatings on plain titanium substrates, and also that the formation of substrates with a complicated surface topographies, ${ }^{9}$ is experimentally feasible. In addition, we have confirmed experimentally that the ion source, the molar ratio of $\mathrm{Ca} / \mathrm{P}$ in the solution, and the surface roughness of the substrate affect the precipitate, $8,10,11)$ and the osteoconductive properties depend significantly on the surface morphology of the $\mathrm{HAp}^{12,13)}$ and the carbonate content in the coatings. ${ }^{14)}$

In this work, HAp/collagen and HAp/denatured collagen (gelatin) composite-coated films were formed on titanium substrates using a thermal substrate method in a solution containing acid-soluble collagen (Type I). In addition, the coated samples were implanted in a rat's tibia for a period of $14 \mathrm{~d}$ to evaluate the extent of new bone formation.

\section{Materials and Methods}

\subsection{HAp/collagen and HAp/denatured collagen com- posite coatings}

The experimental apparatus and procedure used to fabricate the HAp/collagen and HAp/denatured collagen coatings was almost the same as those discussed in previous reports on HAp coatings, ${ }^{8,9,12-14)}$ therefore they will only be described in brief here. The aqueous solution used consisted of $0.3 \mathrm{mM} \mathrm{Ca}\left(\mathrm{H}_{2} \mathrm{PO}_{4}\right)_{2}, 0.7 \mathrm{mM} \mathrm{CaCl}_{2}$, and $\sim 432 \mathrm{mg} \mathrm{dm}^{-3}$ acid-soluble collagen (Type I) derived from calves (Nitta Gelatin Inc.), where the unit " $\mathrm{M}$ " denotes mol dm ${ }^{-3}$. The $\mathrm{pH}$ of the solution was adjusted to $\mathrm{pH}=8$ by the addition of aqueous $\mathrm{NaOH}$ solution, ${ }^{10,11)}$ whereupon the solution cloud- 
ed slightly because of the gelation of the collagen. Commercial pure titanium rods $(\phi=2 \mathrm{~mm}, l=5 \mathrm{~mm})$ and plates (thickness $=0.3 \mathrm{~mm}$ ) were polished with $\mathrm{SiC}$ emery paper (\#400 grid) before the coating experiments were carried out. The samples were connected between copper electrodes, immersed in $0.2 \mathrm{dm}^{3}$ of aqueous solution, and shaken to release any air bubbles that may have adhered to their surfaces. An alternating current (up to $50 \mathrm{~A}$ ) was passed through the samples via the copper electrodes, which heated the samples. The temperature of the sample was measured using a calibrated thermocouple, which was in contact with the surface of the samples. The temperature was maintained at 40,60 , or $140^{\circ} \mathrm{C}$ for a period of 15 or $30 \mathrm{~min}$. using the current amplitude, and switching the power off terminated the coating process. In the low temperature experiments carried out at 40 and $60^{\circ} \mathrm{C}$, HAp did not precipitate easily on the substrates using the above solution. Therefore, ethanol (1 M), which decreases the solubility of HAp in an aqueous solution, ${ }^{15)}$ was added to the solutions. During Joule heating, a $100 \mathrm{kHz}$ ultrasonic wave, which accelerates the nucleation of HAp, ${ }^{16)}$ was applied to the samples using an ultrasonic cleaning apparatus, and the coating period was extended by a period of $30 \mathrm{~min}$. During the coating process, the solution was water-cooled to prevent any increase in temperature, and the solution temperature was kept at $15^{\circ} \mathrm{C}$. The coated samples were studied using a coulometric method, to determine the collagen or the denatured collagen content, $\mathrm{X}$-ray diffraction (XRD), and scanning electron microscopy (SEM).

\subsection{Quantitative analysis of collagen or gelatin in the coatings}

The collagen or the denatured collagen content in the composite films was analyzed using a coulometric method (Coulomatic "C"). ${ }^{14,17)}$ The quantitative analysis of collagen or denatured collagen in the coatings was carried out after storing in a vacuum desiccator for periods $>48 \mathrm{~h}$, and we confirmed that the mass of the samples remained constant, as the composite films had measurable moisture. The coated samples (i.e., titanium substrates with a coated film) were placed on a mullite boat and calcined at $600^{\circ} \mathrm{C}$ under an $\mathrm{O}_{2}$ atmosphere for an extraction time of $4 \mathrm{~min}$. The $\mathrm{CO}_{2}$ evolved was absorbed in an aqueous solution that contained barium perchlorate, and the amount of $\mathrm{CO}_{2}$ absorbed was analyzed coulometrically. The collagen or denatured collagen content in the coating was calculated from the carbon content. Pure collagen (GR, Nacalai Tesque, Inc) was used as a reference material in the analysis of the collagen or denatured collagen content in the composite films. By placing both pure collagen and as-polished titanium substrate in the mullite boat, and analyzing the collagen content based on the above extraction conditions, the analytical error limit was confirmed to be $<5 \%$. However, as the collagen is the trimer of gelatin (denatured collagen), we could not obtain the collagen and denatured collagen content of the composites separately using above method. In addition, we have reported that the thermal substrate method partially gives the carbonate apatite (Type B $)^{14)}$ using the above coating conditions without any collagen being added. However, it was confirmed that the carbonate in the films and the carbon in the titanium substrates was not extracted using the above analytical conditions, and thus, the amount of carbonate ions in the coated apatite and also the amount of soluted carbon in the titanium substrate could be ignored. Therefore, the quantitative value under the above conditions was considered as being the collagen or denatured collagen content in the composite films.

\subsection{In vivo study}

All animal handling and surgical procedures were conducted according to guidelines in Hamri co., ltd. The experimental procedure for our in vivo study was almost the same as described in previous reports, ${ }^{10,11,14)}$ therefore it is only described in brief here. Before surgery, all the implants were cleaned in distilled water and immersed in a chlorhexidine gluconate solution. However, they were not sterilized in a steam autoclave to prevent the collagen becoming denatured and the gelatine being dissolved. Tenweek-old male Sprague Dawley rats (Charles River Japan, Inc.) were used in our experimental procedure. The samples were implanted in the tibial metaphysis of the rats. A slightly oversized hole, which did not pass through to the backside of the bone, was created using a low-speed rotary drill. Subsequently, the implants were inserted in these holes, and then, the subcutaneous tissue and skin were closed and sterilized.

The rats were sacrificed after a period of $14 \mathrm{~d}$, and the implants with their surrounding tissue were retrieved. The samples were fixed in a $10 \%$ neutral buffered formalin solution, dehydrated in a graded series of ethanol, and embedded in methylmethacrylate. Following polymerization, each implant block was sectioned into slices that were $20 \mu \mathrm{m}$ thick. These sections were then stained with toluidine blue.

The sum of the linear bone contact with the implant surface was measured and expressed as a percentage over the entire implant length (the bone-implant contact ratio, $R_{\mathrm{B}-\mathrm{I}}$ ) in the cancellous bone and the cortical bone parts. Significant differences in the bone-implant contact ratio were analyzed statistically using the Tukey-Kramer method. Differences were considered statistically significant at $p<0.05$.

\section{Results and Discussion}

\subsection{Denaturalization of collagen}

As mammalian collagen denatures to form gelatin at temperatures $>40-50^{\circ} \mathrm{C}$, as mentioned above, there was the possibility that the collagen would denature on the substrate during the coating process using the thermal substrate method at $40-140^{\circ} \mathrm{C}$. To confirm whether this denaturalization had taken place, the following experiments were conducted. Solutions $\left(0.015 \mathrm{dm}^{-3}\right)$ were prepared that consisted of $0.3 \mathrm{mM} \mathrm{Ca}\left(\mathrm{H}_{2} \mathrm{PO}_{4}\right)_{2}, 0.7 \mathrm{mM} \mathrm{CaCl} 2,1 \mathrm{M}$ ethanol, and $5 \mathrm{~g} \mathrm{dm}^{-3}$ acid-soluble collagen (Type I), and these were adjusted to $\mathrm{pH}=8$. The solutions were heated in a water bath up to the desired experimental temperature, and maintained at that temperature for a period of up to $30 \mathrm{~min}$. After heating, the solution in a beaker was removed from the water bath and air-cooled to room temperature. The results are listed in Table 1, where "+" denotes that the solutions became gellike after cooling, and "-" denotes that the solutions did not 
Table 1 Effect of temperature and heating time on denaturation of collagen.

\begin{tabular}{cccccc}
\hline & & \multicolumn{5}{c}{ Heating time, $t /$ min. } \\
\cline { 2 - 5 } & & 5 & 10 & 15 & 30 \\
\hline \multirow{2}{*}{$\begin{array}{c}40 \\
\text { Temperature } \\
T /{ }^{\circ} \mathrm{C}\end{array}$} & - & - & - & - & - \\
\cline { 2 - 5 } & 50 & - & + & + & + \\
\cline { 2 - 5 } & $60 \sim$ & + & + & + & + \\
\hline
\end{tabular}

-: not change

+ : denaturation (gelatinization)

change under visual observation. This experiment was based on the fact that the solutions containing gelatin would jell after cooling, and those that contained collagen would not. From Table 1, it can be seen that collagen denatured rapidly at $>60^{\circ} \mathrm{C}$, and even at $50^{\circ} \mathrm{C}$ within a period of $10 \mathrm{~min}$. On the other hand, the denaturalization of collagen was not observed at $40^{\circ} \mathrm{C}$ until $30 \mathrm{~min}$. Therefore, it is thought that the composite coatings at $>50^{\circ} \mathrm{C}$ gave $\mathrm{HAp} /$ denatured collagen films, and those at $40^{\circ} \mathrm{C}$ gave $\mathrm{HAp} /$ collagen films. In this paper, denatured collagen is denoted by "gelatin" for simplicity.

\subsection{HAp/collagen and HAp/gelatin composite coatings}

Typical SEM photographs of the surface of the samples coated at $40-140^{\circ} \mathrm{C}$ for a period of 15 or $30 \mathrm{~min}$. are shown in Fig. 1. The variation in collagen or gelatin content in the films is shown in Fig. 2. The addition of collagen to the solution decreased the amount of precipitate on the titanium substrates slightly compared to coatings from solutions that had no added collagen. A white precipitate covered the entire surface of the samples coated at $140^{\circ} \mathrm{C}$ after a period of $15 \mathrm{~min}$. Ultrasonic waves at $100 \mathrm{kHz}$ were applied during the coating procedure in a solution that had $1 \mathrm{M}$ ethanol added, as the substrates were not completely covered with precipitate, even after a period of $30 \mathrm{~min}$. at 40 and $60^{\circ} \mathrm{C}$. However, in the case where $>216 \mathrm{mg} \mathrm{dm}^{-3}$ of collagen was added at $40^{\circ} \mathrm{C}$ and where $432 \mathrm{mg} \mathrm{dm}^{-3}$ of collagen was added at $60^{\circ} \mathrm{C}$, the substrates were not covered entirely with precipitate using the above coating conditions.

The precipitates coated from a solution contained collagen at all temperatures were identified as HAp by XRD analysis. Strictly speaking, the HAp here should be expressed as "carbonate apatite" as the obtained coatings contained carbonate, as discussed in our previous paper. ${ }^{14)}$ However, here we will denote this by simply HAp. When using a collagen-free solution, the low-temperature coatings $\left(40^{\circ} \mathrm{C}\right)$ formed a net-like precipitate ((j) in Fig. 1), the high-temperature coatings $\left(140^{\circ} \mathrm{C}\right)$ formed a needle-like precipitate ((a) in Fig. 1), and the mid-temperature range coatings $\left(60^{\circ} \mathrm{C}\right)$ formed a plate-like precipitate ((f) in Fig. 1). On the other hand, when the coatings were carried out in a solution containing collagen, the HAp crystals kept their hexagonal rod shape in the $140^{\circ} \mathrm{C}$ coatings, although the amount of precipitate decreased. This means that gelatin did not have a significant influence on the specific adsorption on the HAp. Moreover, a fibriform component was found in the films in the solutions with a collagen content of 216 and $432 \mathrm{mg} \mathrm{dm}^{-3}$ collagen content at $140^{\circ} \mathrm{C}((\mathrm{d})$ and (e) in Fig. 1, respectively).
At 40 and $60^{\circ} \mathrm{C}$, the morphology of these coatings was similar and they exhibited a large plate-like morphology, despite the differences between collagen and gelatin. In addition, we did not observe fibrous or gel-like substances either on the surface or inside these films. However, according to the chemical analysis, it is thought that that collagen or gelatin content (Fig. 2) indicated that the films contained either collagen or gelatin, which had dispersed inside the films. The change in collagen content $\left(40^{\circ} \mathrm{C}\right)$ or gelatin content $\left(60^{\circ} \mathrm{C}\right)$ in the films formed from solutions with added collagen was also similar. However the surface morphology of the HAp/gelatin composites in the $60^{\circ} \mathrm{C}$ and $140^{\circ} \mathrm{C}$ coatings was different. That is to say, the surface morphology of the HAp/collagen and HAp/gelatin coatings depended significantly on the coating temperature, and was not affected by whether the composite film contained collagen or gelatin. Thus, it is thought that both gelatin and collagen do not have an inhibitory effect on the precipitation of HAp by their adsorption on HAp. However, the change in viscosity of the solutions near the substrates because of the difference in the coating temperature affected the surface morphology of the coatings. It is supported that the change in viscosity of the solutions resulted in the decrease of the precipitate by the addition of collagen to the solution in the low temperature coatings. In addition, the change in viscosity of the solutions influenced the collagen or gelatin content in the films. It was possible to control the collagen or gelatin content from 10 to 60 mass $\%$ in the composite films, despite the differences in collagen content in the solutions and the surface morphology.

\subsection{In vivo study}

Figure 3 shows the relationship between the bone-implant contact ratio, $R_{\mathrm{B}-\mathrm{I}}$, of the coated samples at a period of $14 \mathrm{~d}$ after implantation, along with the collagen or gelatin content in the coatings classified using the following surface morphology and content in the composite films: (A) needlelike (HAp/gelatin), (B) plate-like (HAp/gelatin), and (C) plate-like (HAp/collagen). These classifications were compared with the control implant (non-coated titanium, (E)). The samples are distinguished using different colors in Fig. 3 according to whether the coatings contained collagen, gelatin, or neither (black: collagen, gray: gelatin, and white: neither, i.e., only HAp).

\subsubsection{HAp/gelatin coatings}

In the cancellous bone part(2) in Fig. 3 , the $R_{\mathrm{B}-\mathrm{I}}$ value of the coatings with HAp/gelatin in any content (the gray bars in (A) and (B)) was almost the same as the coatings with only HAp (white bars in (A) and (B)) and the control titanium sample (E). On the other hand, in the cortical bone part (1), $R_{\mathrm{B}-\mathrm{I}}$ value of the HAp/gelatin coatings ((A) and (B)) was higher than that of the coatings with only HAp and the control for all gelatin contents. That is, the osteoconductivity in the cortical bone part (1) was slightly improved. However, in the cancellous bone part (2), the improvement in osteoconductivity using HAp/gelatin coatings was not very high. It is reported that the morphology and size of implanted HAp affected the intrusion of bone marrow, ${ }^{18)}$ moreover, we also revealed that the surface morphology of HAp influenced the osteoconductivity. ${ }^{12,13)}$ However, the effect of the differ- 

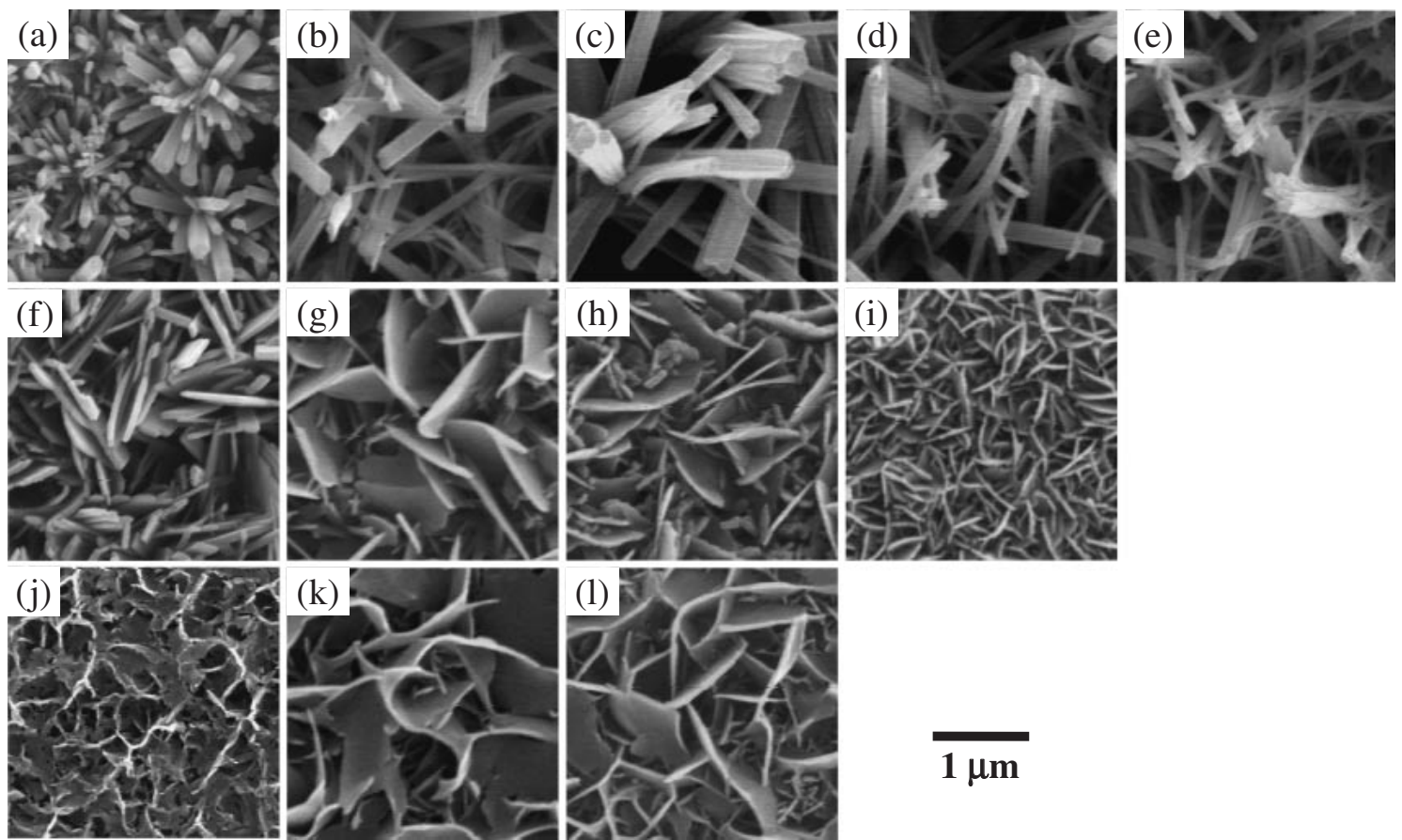

\section{$1 \mu \mathrm{m}$}

\begin{tabular}{|c|c|c|c|c|c|c|c|c|c|}
\hline & \multicolumn{5}{|c|}{ Solution } & \multicolumn{3}{|c|}{ Coating } & \multirow{3}{*}{$\begin{array}{c}\text { Film } \\
\text { componen }\end{array}$} \\
\hline & \multicolumn{2}{|c|}{$\begin{array}{c}\text { Content } \\
\text { / mM }\end{array}$} & $\begin{array}{l}\text { Content } \\
/ \mathrm{mg} \mathrm{dm}^{-3}\end{array}$ & \multirow[t]{2}{*}{$\mathrm{pH}$} & \multirow{2}{*}{$\begin{array}{c}\text { Addition } \\
\text { of EtOH } \\
(1 \mathrm{M})\end{array}$} & \multirow{2}{*}{$\begin{array}{c}\text { Ultrasonic } \\
\text { wave } \\
(100 \mathrm{kHz})\end{array}$} & \multirow{2}{*}{$\begin{array}{l}\text { Temp, } \\
T /{ }^{\circ} \mathrm{C}\end{array}$} & \multirow{2}{*}{$\begin{array}{l}\text { Time, } \\
t / \mathrm{min} .\end{array}$} & \\
\hline & $\mathrm{Ca}\left(\mathrm{H}_{2} \mathrm{PO}_{4}\right)_{2}$ & $\mathrm{CaCl}_{2}$ & collagen & & & & & & \\
\hline (a) & \multirow{12}{*}{0.3} & \multirow{12}{*}{0.7} & - & \multirow{12}{*}{8} & \multirow{5}{*}{-} & \multirow{5}{*}{-} & \multirow{5}{*}{140} & \multirow{5}{*}{15} & HAp \\
\hline (b) & & & 72 & & & & & & \multirow{4}{*}{$\begin{array}{c}\text { HAp } \\
\text { /gelatine }\end{array}$} \\
\hline (c) & & & 144 & & & & & & \\
\hline (d) & & & 216 & & & & & & \\
\hline (e) & & & 432 & & & & & & \\
\hline (f) & & & - & & \multirow{7}{*}{ O } & \multirow{7}{*}{0} & \multirow{4}{*}{60} & \multirow{7}{*}{30} & HAp \\
\hline (g) & & & 72 & & & & & & \multirow{3}{*}{$\begin{array}{c}\text { HAp } \\
\text { /gelatine }\end{array}$} \\
\hline (h) & & & 144 & & & & & & \\
\hline (i) & & & 216 & & & & & & \\
\hline (j) & & & - & & & & \multirow{3}{*}{40} & & HAp \\
\hline (k) & & & 72 & & & & & & HAp \\
\hline (l) & & & 144 & & & & & & /Collagen \\
\hline
\end{tabular}

Fig. 1 Surface morphology of the samples, coated for 15 or $30 \mathrm{~min}$. in the solution at $\mathrm{pH}=8$ containing $0.3 \mathrm{mM} \mathrm{Ca}\left(\mathrm{H}_{2} \mathrm{PO}\right)_{2}, 0.7 \mathrm{mM}$ $\mathrm{CaCl}_{2}$ and collagen. temperature: (a) (e) $140^{\circ} \mathrm{C}$, (f) (i) $60^{\circ} \mathrm{C}$, (j) $\sim(\mathrm{l}) 40^{\circ} \mathrm{C}$ collagen content: (a)(f)(j) no addition, (b) $(\mathrm{g})(\mathrm{k}) 72 \mathrm{mg} \mathrm{dm}{ }^{-3}$, (c)(h)(l) $144 \mathrm{mg} \mathrm{dm}^{-3}$, (d)(i) $216 \mathrm{mg} \mathrm{dm}^{-3}$, (e) $432 \mathrm{mg} \mathrm{dm}^{-3}$.

ence in the surface morphology of HAp in the HAp/gelatin was not clear.

\subsubsection{HAp/collagen composite coatings}

In the plate-like HAp/collagen composite films (C), the value of $R_{\mathrm{B}-\mathrm{I}}$ in the cancellous part (2) was almost the same as the coating with only HAp and the control titanium sample in the same manner as the HAp/gelatin coatings ((A) and (B)). However, the value of $R_{\mathrm{B}-\mathrm{I}}$ in the cortical bone part (1)(C) increased with increasing collagen content up to about 30 mass \%, which is in agreement with the collagen content in natural bone. In contrast, an addition of collagen to 40 mass $\%$ decreased the value of $R_{\mathrm{B}-\mathrm{I}}$. It is thought that the HAp and collagen composite, whose content was up to about 30 mass $\%$, enhanced the osteoconductivity beyond that of HAp/gelatin composites and individual HAp coatings, as a result of the collagen acting as a cell-binding protein. ${ }^{6}$ ) However, too much collagen in the composite films did not lead to further improvement of the osteoconductivity. We think that this is because the ratio of HAp to collagen in the films is mismatched compared to natural bone. On the other hand, in the cancellous bone part with a good circulation of body fluid, the value of $R_{\mathrm{B}-\mathrm{I}}$ was close to the value in normal cancellous bone within the 2 weeks implantation, either in the presence or absence of collagen in the films. Therefore, it was 


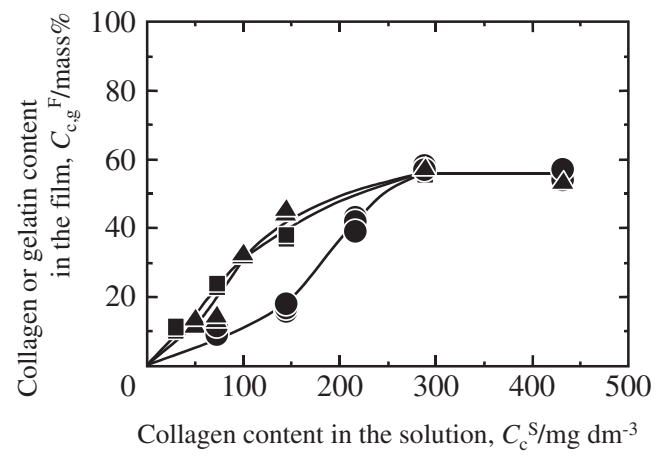

Fig. 2 Relationship between collagen or gelatin content in the coating and collagen content in the solution. $140^{\circ} \mathrm{C}, \boldsymbol{\square}: 60^{\circ} \mathrm{C}, \boldsymbol{\Delta}: 40^{\circ} \mathrm{C}$.

thought that the effect of the composite films with collagen on the osteoconductivity is not clear in the cancellous bone parts.

\subsubsection{HAp/collagen composite coatings using a two-step process}

As the needle-like HAp coatings exhibited the highest osteoconductivity in the several surface morphologies of HAp, ${ }^{12,13)}$ we thought that a composite with needle-like HAp and collagen would demonstrate a higher osteoconductivity than plate-like HAp/collagen composites would, as dis- cussed above. However, a needle-like HAp/collagen composite could not be obtained using the one-step process of the thermal substrate method, because needle-like HAp forms at higher temperatures than the denaturalization temperature of collagen. Therefore, such a composite was formed using the following two-step method.

A needle-like HAp coating was prepared using the thermal substrate method in the same solutions as described earlier that did not contain collagen at $140^{\circ} \mathrm{C}$ for $15 \mathrm{~min}$. Then, the substrates with needle-like HAp were immersed and shook in a solution containing $216 \mathrm{mg} \mathrm{dm}^{-3}$ of collagen at a $\mathrm{pH}=8$ at $20^{\circ} \mathrm{C}$ for $15 \mathrm{~min}$. After the substrates were taken out of the solution, the samples were rinsed in water, and then dried.

An SEM photograph of the surface of a two-step composite sample is shown in Fig. 4. It can be seen that the collagen gel was attached to parts of the surface on the needle-like HAp. Observation of the cross-section of the coated samples showed that the collagen gel did not penetrate into the needle-like HAp crystals that had been coated in advance. In addition, the two-step composite films contained about 5 mass $\%$ of collagen, and this value is very much lower than that of natural bone. The $R_{\mathrm{B}-\mathrm{I}}$ value of the two-step composite is shown in Fig. 3(D). It was lower than that of the needle-like HAp samples without collagen in the cancellous and cortical bone parts (the white bars in Fig. 3(A)). It is thought that this is the reason why a collagen cover had a bad

(A)

(B)

(C)

(D) (E)

(1)

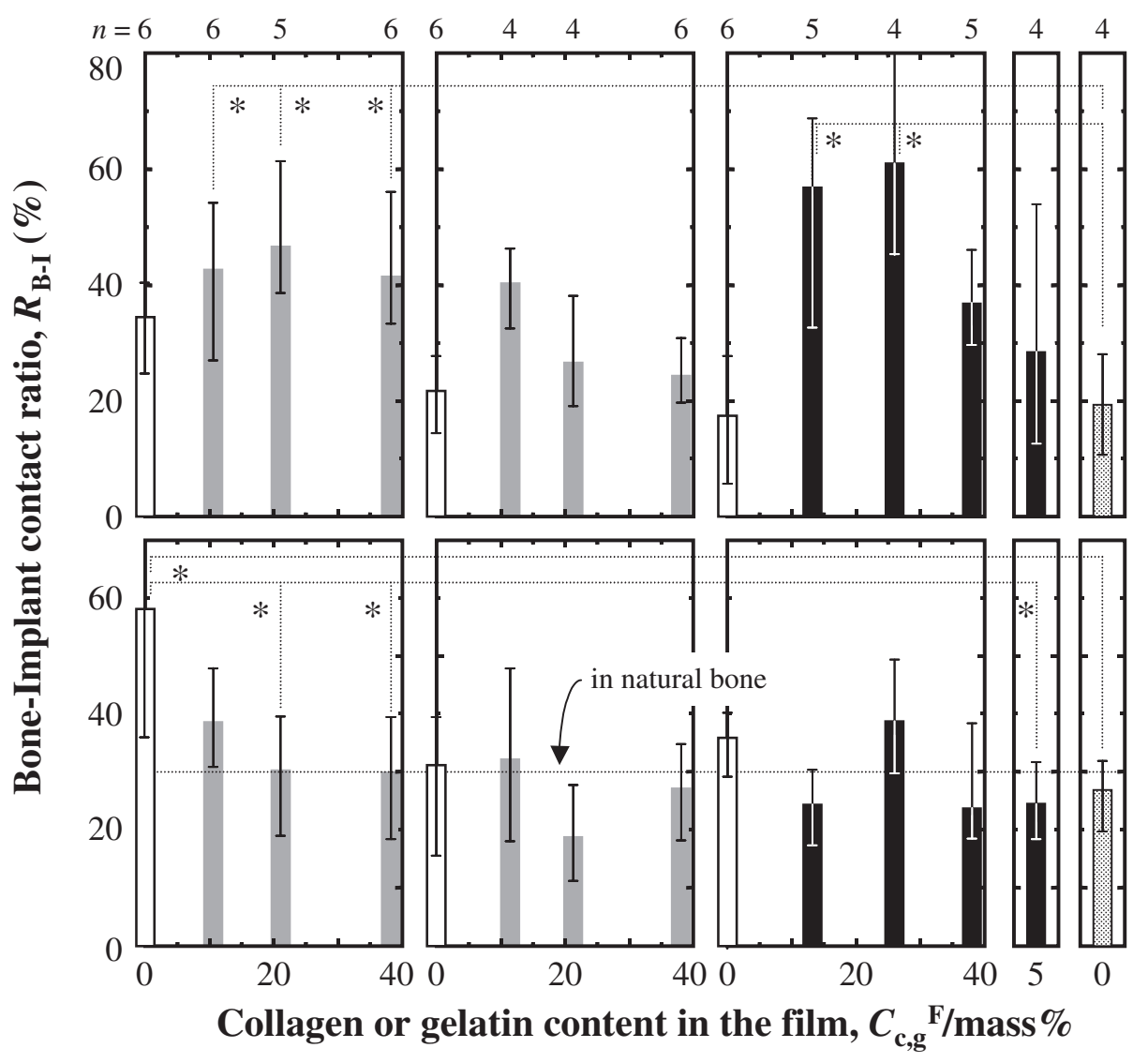

Fig. 3 Bone-Implant contact ratio, $R_{\mathrm{B}-\mathrm{I}}$, showing the percentage of bone formed on the coated implants with various surface morphologies and gelatin or collagen content. $\square$ : HAp/collagen, $\square$ : HAp/gelatin, $\square$ : HAp (1) cortical bone and (2) cancellous bone (A) needle-like, (B)(C) plate-like, (D) needle-like (two-step composite) and (E) control Ti. ${ }^{*} p<0.05$. 


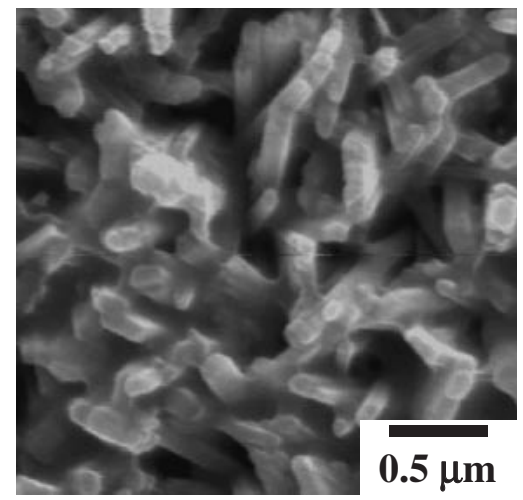

Fig. 4 SEM photograph of the surface of the composite sample using the two-step coating process.

influence on the osteoconductivity of the needle-like HAp samples. In other words, the composite in the form of HAp covered with collagen, like the one formed in the two-step coating above produced a negative effect on the osteoconductivity. Thus, the osteoconductivity of the HAp/collagen samples depends on the composite structure of the HAp and collagen. Our experimental results indicate that the composite in the form where the collagen is dispersed in the interspaces of the HAp crystals, as is formed using the thermal substrate method at low temperature, significantly enhances the osteoconductivity, rather than the form where the collagen is covered on the HAp crystals.

\section{Conclusions}

(1) HAp/collagen and HAp/gelatin composite coatings were obtained using a thermal substrate method in aqueous solutions that contained $\mathrm{Ca}\left(\mathrm{H}_{2} \mathrm{PO}_{4}\right)_{2}, \mathrm{CaCl}_{2}$, and acid-soluble collagen (Type I), by changing the coating temperature and the collagen content in the solutions. The HAp crystals exhibited a hexagonal rod morphology in the HAp/gelatin composite coatings formed at $140^{\circ} \mathrm{C}$. The surface morphology of the HAp/ gelatin composites coated at $60^{\circ} \mathrm{C}$ was plate-like, and was similar to that of $\mathrm{HAp} /$ collagen coated at $40^{\circ} \mathrm{C}$. It was possible to control the collagen or gelatin content from 10 to 60 mass $\%$ in all the composite films.

(2) In the HAp/collagen composite samples, the boneimplant contact ratio $R_{\mathrm{B}-\mathrm{I}}$ increased with increasing collagen content up to about 30 mass $\%$, and at $>30$ mass $\%, R_{\mathrm{B}-\mathrm{I}}$ decreased in cortical bone parts. On the other hand, the value of $R_{\mathrm{B}-\mathrm{I}}$ in the coatings with any HAp/gelatin content was slightly higher than that of only HAp coatings and the control titanium sample. However, the value of $R_{\mathrm{B}-\mathrm{I}}$ in the HAp/gelatin samples was lower than that of HAp/collagen composites. In the HAp/collagen composites, it is thought that the composite in the form where the collagen is dispersed in the interspaces of the HAp crystals, as is formed using the thermal substrate method at low temperature, enhanced the osteoconductivity significantly.

\section{Acknowledgment}

This work was partially supported by a Grant-in-Aid for Young Scientist (B) (No. 17760564) from the Japan Society for the Promotion of Science (JSPS).

\section{REFERENCES}

1) L. L. Hench and J. Wilson: An Introduction to Bioceramics, (World Scientific, Singapore, 1993).

2) H. Aoki: Marvelous Biomaterial, Apatite, (Ishiyaku Publishers, Inc., 1999) p. 19 (in Japanese).

3) M. C. Chang, T. Ikoma, M. Kikuchi and J. Tanaka: J. Mater. Sci. Lett. 20 (2001) 1199-1201.

4) R. Z. Wang, F. Z. Cui, H. B. Lu, H. B. Wen, C. L. Ma and H. D. Li: J. Mater. Sci. Lett. 14 (1995) 490-492.

5) M. C. Chang, C. Ko and W. Douglas: Biomater. 24 (2003) 2853-2862.

6) T. Ishii, M. Koishi and T. Tsunoda: Nure-gijutsu handbook, (Technosystem, Tokyo, 2001), Chap. 16 (in Japanese).

7) T. Okada and Y. Ikada: J. Biomater. Sci. Polymer Edn. 7 (1995) 171180.

8) K. Kuroda, R. Ichino, M. Okido and O. Takai: J. Biomed. Mater. Res. 59 (2002) 390-397.

9) K. Kuroda, S. Nakamoto, R. Ichino, M. Okido and R. M. Pilliar: Mater. Trans. 46 (2005) 1633-1635.

10) K. Kuroda, R. Ichino, M. Okido and O. Takai: J. Biomed. Mater. Res. 61 (2002) 354-359.

11) K. Kuroda, Y. Miyashita, R. Ichino, M. Okido and O. Takai: Mater. Trans. 43 (2002) 3015-3019.

12) K. Kuroda, S. Nakamoto, Y. Miyashita, R. Ichino and M. Okido: Mater. Trans. 47 (2006) 1931-1934.

13) K. Kuroda, S. Nakamoto, Y. Miyashita, R. Ichino and M. Okido: J. Jpn. Inst. Metals 71 (2007) 342-345.

14) K. Kuroda, M. Moriyama, R. Ichino, M. Okido and A. Seki: Mater. Trans. 49 (2008) 1434-1440.

15) M. S. Tung and T. J. O'Farrell: Coll. Surf. A 110 (1996) 191-198.

16) Y. Fang, D. K. Agarwal, D. M. Roy, R. Roy and P. W. Brown: J. Mater. Res. 7 (1992) 2294-2298.

17) K. Koyama and Y. Hashimoto: J. Jpn. Inst. of Metals 51 (1987) 678685.

18) T. Matsumoto, K. Tamine, R. Kagawa, Y. Hamada, M. Okazaki and J. Takahashi: J. Ceram. Soc. Jpn. 114 (2006) 760-762. 